\title{
The Brain Adenylyl Cyclase Signaling System and Cognitive Functions in Rats with Neonatal Diabetes under the Influence of Intranasal Serotonin
}

\author{
Alexander O Shpakov ${ }^{1 *}$, Kira V Derkach ${ }^{1}$, Oksana V Chistyakova ${ }^{1}$, Ivan B Sukhov ${ }^{1}$, Valery N Shipilov ${ }^{1}$ and Vera M Bondareva ${ }^{1}$ \\ Sechenov Institute of Evolutionary Physiology and Biochemistry, Russian Academy of Sciences, Thorez av. 44, 194223 St. Petersburg, Russia
}

\begin{abstract}
Type 2 diabetes mellitus is often associated with the neurodegenerative changes, and this is regarded as being the cause of cognitive deficit and other brain dysfunctions. The data obtained by us and the other authors showed that alterations in the brain signaling systems regulated by different hormones and neurotransmitters contribute to triggering and development of neurodegenerative processes in diabetes. However, the activity of brain adenylyl cyclase system and the cognitive functions, their interrelation, and the influence of intranasal serotonin on them in type 2 diabetes are poorly understood yet. We investigated the hormonal sensitivity of adenylyl cyclase system in the brain of female rats with the neonatal model of type 2 diabetes and the influence of 8-weeks treatment with intranasal serotonin $(20 \mu \mathrm{g} / \mathrm{rat}$ daily) on the brain adenylyl cyclase system and cognition in diabetes. It was shown that in the diabetic brain the regulatory effects of hormones (relaxin, adrenergic agonists, dopamine, serotonin) activating adenylyl cyclase via Gs proteins changed in a receptor-specific manner and were restored by intranasal serotonin. The effects of hormones inhibiting adenylyl cyclase via $\mathrm{Gi}$ proteins were significantly decreased, especially in the case of agonists of type 1 serotonin receptors. The intranasal serotonin treatment led to their partial or complete restoration. Using Morris water maze test we showed that intranasal serotonin improves diabetesassociated impaired learning and spatial memory. Summing up, in the brain of diabetic rats the functional activity of hormone-sensitive adenylyl cyclase signaling system was altered, most dramatically in the G-coupled cascades. The intranasal serotonin treatment improved both the signal transduction via the brain adenylyl cyclase system and cognitive functions in type 2 diabetes.
\end{abstract}

Keywords: Adenylyl cyclase; Brain; Cognition; Diabetes mellitus; Dopamine; 5-hydroxytryptamine receptor; Intranasal serotonin; Morris water maze test; Somatostatin; Spatial memory

Abbreviations: AC: Adenylyl Cyclase; AR: Adrenergic Receptor; DAR: Dopamine Receptor; DM: Diabetes Mellitus; EMD-386088: 5-chloro-2-methyl-3-(1,2,3,6-tetrahydro-4-pyridinyl)-1H-indole; $\mathrm{G}_{\mathrm{s}}$ and $\mathrm{G}_{\mathrm{i}}$ proteins: Heterotrimeric $\mathrm{G}$ proteins of the stimulating and inhibitory types, respectively; GppNHp, $\beta, \gamma$-imidoguanosine5'-triphosphate; 5-HT, 5-hydroxytryptamine (serotonin); 5-HTR, 5-Hydroxytryptamine Receptor; IS: Intranasal Serotonin; 5-MeODMT: 5-Methoxy-N,N-Dimethyltryptamine; MWM test: Morris Water Maze Test; PACAP-38: Pituitary Adenylyl Cyclase-Activating Polypeptide-38; STZ: Streptozotocin; T1DM and T2DM: Types 1 and 2 Diabetes Mellitus.

\section{Introduction}

Diabetes mellitus (DM) is one of the most severe metabolic disorders in humans characterized by hyperglycemia due to a relative or an absolute lack of insulin or its action on the target tissue or both. Many neurodegenerative disorders, such as diabetic encephalopathy and Alzheimer's disease, are associated with the types 1 and 2 diabetes mellitus (T1DM and T2DM) [1]. Manifestation of these disorders in diabetic patients includes alterations in neurotransmission, electrophysiological abnormalities, structural changes and cognitive deficit [2]. In the case of T2DM it is generally accepted that the main factors responsible for the neurodegenerative changes are the resistance of the peripheral tissues to insulin action, which leads to moderate hyperglycemia, and the recurrent hypoglycemia induced by inadequate insulin therapy and glycemic control [3]. Recently, many evidences have been obtained to the effect that the alterations and abnormalities of hormonal signaling systems regulated by insulin, insulin-like growth factor-1, leptin, biogenic amines, and peptide hormones controlling fundamental processes in the neuronal and glial cells contribute to triggering and development of neurodegenerative changes in the diabetic brain $[4,5]$. In our view, the changes in the brain signaling systems, on the one hand, may be due to formation of a compensatory response to physiological and biochemical dysfunctions occurring in $\mathrm{DM}$, and, on the other hand, may themselves be the cause of these dysfunctions.

Earlier we and the other authors showed that in human DM and animal models of this disease the functioning of hormone-sensitive adenylyl cyclase (AC) signaling system undergoes changes in tissueand hormone-specific manner [6-11]. In both types of DM the most pronounced alterations were found in the regulation of AC activity by hormones inhibiting the enzyme via heterotrimeric $G$ proteins of the inhibitory type $\left(G_{i}\right)[6,7,10,11]$. At the same time, the functional state of AC signaling system in the brain of rats with experimental models of T2DM and the regulation of AC activity by hormones interacting with $G$ proteins of the stimulatory type $\left(G_{s}\right)$ or $G_{i}$ proteins, or activating simultaneously both $\mathrm{G}$ protein types, have not been investigated. The study of AC signaling in the diabetic brain may throw light on the molecular mechanisms of neurodegeneration in human T2DM; it may also be helpful in finding new approaches for the treatment of T2DMinduced cognitive deficit and neurological disorders.

Now insulin is commonly accepted as drug to be used in treatment of T1DM as well as T2DM, especially when $\beta$ cell function falls [12]. Usually, insulin is injected subcutaneously, but recently the other ways of delivery of hormone and its analogues, such as oral and intranasal,

Corresponding author: Alexander O. Shpakov, Sechenov Institute of Evolutionary Physiology and Biochemistry, Russian Academy of Sciences, Thorez av. 44, 194223 St. Petersburg, Russia, Tel: +7-812-552-31-17; Fax: +7-812-552-30-12; E-mail: alex_shpakov@list.ru

Received December 02, 2011; Accepted January 27, 2012; Published February 18, 2012

Citation: Shpakov AO, Derkach KV, Chistyakova OV, Sukhov IB, Shipilov VN, et al. (2012) The Brain Adenylyl Cyclase Signaling System and Cognitive Functions in Rats with Neonatal Diabetes under the Influence of Intranasal Serotonin. J Metabolic Synd 1:104. doi:10.4172/2167-0943.1000104

Copyright: (c) 2012 Shpakov AO, et al. This is an open-access article distributed under the terms of the Creative Commons Attribution License, which permits unrestricted use, distribution, and reproduction in any medium, provided the original author and source are credited. 
Citation: Shpakov AO, Derkach KV, Chistyakova OV, Sukhov IB, Shipilov VN, et al. (2012) The Brain Adenylyl Cyclase Signaling System and Cognitive Functions in Rats with Neonatal Diabetes under the Influence of Intranasal Serotonin. J Metabolic Synd 1:104. doi:10.4172/21670943.1000104

Page 2 of 9

have been used. Intranasal insulin allows successful glycemic control, improves learning and memory and prevents cognitive decline in diabetic patients [13]. This is confirmed by our findings that the therapy of rats with T2DM by intranasal insulin normalizes the functioning of insulin signaling system, restores cAMP-dependent signaling cascades and improves their cognitive functions [11,14]. However, in the recent years, along with insulin in the treatment of T2DM and pre-diabetic state and, first of all, to correct DM-associated neurodegenerative diseases, have been widely used bromocriptine, a selective agonist of type 2 dopamine receptor $\left(\mathrm{DA}_{2} \mathrm{R}\right)$ [15], and the selective serotonin (5$\mathrm{HT})$ reuptake inhibitors [16]. It was found that both bromocriptine and 5 -HT reuptake inhibitors increase the brain serotonin level markedly decreased in DM $[15,17]$. The data is available suggesting that abnormalities in the serotonergic system in the diabetic brain provoke disturbances in neuronal processing, induce alteration of the plasticity of neurotransmission and, thus, play an important role in DM-induced behavioral abnormalities, therefore there are all reasons to expect that the increased level of brain serotonin will lead to restoration of the serotonin signaling in the brain and improve the impaired cognitive functions [17]. With this in mind, we made an attempt to examine the influence of intranasal route of serotonin delivery on the functioning of the brain in rats with $\mathrm{T} 2 \mathrm{DM}$

The aim of this work was to study the functional state and hormonal sensitivity of AC signaling system in the brain of female rats with the neonatal model of T2DM and to investigate the influence of 8-weeks intranasal serotonin (IS) on this system and cognitive functions in diabetic animals. To determine the specificity of alterations in brain AC system, we studied AC and $\beta, \gamma$-imidoguanosine-5'triphosphate (GppNHp) binding effects of hormones and their analogues activating receptors of the serpentine type coupled with $G_{s}$ or $G_{i}$ proteins. To do this, were chosen the hormones activating $\mathrm{G}_{\mathrm{s}}$-coupled receptors, such as isoproterenol, agonist of $\beta$-adrenergic receptors ( $\beta$-AR), 5-HT ${ }_{6}$-agonist 5-chloro-2-methyl-3-(1,2,3,6-tetrahydro-4-pyridinyl)$1 \mathrm{H}$-indole (EMD-386088), pituitary AC-activating polypeptide-38 (PACAP-38) and relaxin-2, and the hormones activating $\mathrm{G}_{\mathrm{i}}$-coupled receptors, such as $\mathrm{DA}_{2} \mathrm{R}$-agonist bromocryptine, $5-\mathrm{HT}_{1 \mathrm{~B} / \mathrm{D}} \mathrm{R}$ agonist 5-nonyloxytryptamine, 5-HT $\mathrm{H}_{1 / 2}$ R-agonist 5-methoxy-N,N- dimethyltryptamine (5-MeO-DMT) and somatostatin-14, as well as the hormones activating both $\mathrm{G}_{\mathrm{s}}$ - and $\mathrm{G}_{\mathrm{i}}$-coupled receptors, i.e. serotonin, norepinephrine and dopamine (Figure 1). Being involved in the regulation of synaptic plasticity and metabolic and growth processes in neuronal and glial cells, these hormones are very important for the functioning of the central nervous system (CNS). They are also responsible for cellular processes in the peripheral organs and tissues involved in the insulin synthesis and secretion, and thus controlling the glucose homeostasis in the brain and in the whole organism. To detect cognitive deficit in DM and the influence of IS on formation of the long-term spatial memory and learning, a spatial version of the Morris water maze (MWM) test was used.

\section{Materials and Methods}

\section{Animals}

The female Wistar rats were housed in plastic sawdust-covered cages with a normal light-dark cycle and free access to food and water. The experiments were carried out under the Institutional Guidelines (the Bioethics Committee, December 23, 2010) and "Guidelines for the treatment of animals in behavior research and teaching" [18]. All efforts were made to minimize animal suffering and reduce the number of animals used.

Four groups of animals were investigated: control animals $(\mathrm{n}=9$, Group C), IS-treated control animals ( $\mathrm{n}=8$, Group C-S), animals with the neonatal model of T2DM ( $n=7$, Group D), and IS-treated diabetic animals ( $\mathrm{n}=7$, Group D-S).

\section{Neonatal model of T2DM}

Neonatal DM was provoked by intraperitoneal administration of streptozotocin (STZ) dissolved in citrate-acidified solution containing $0.9 \% \mathrm{NaCl}, \mathrm{pH} 4.5$, at the dose of $80 \mathrm{mg} / \mathrm{kg}$ of body weight in newborn (5 days) rats using 26 gauge (5/8 in. long) needle $[19,20]$. The injection site was the dorsal midpoint between pelvis and ribs close to the right side of the spine. Control animals received citrate-acidified physiological solution injected in a similar manner. Typically treatment with STZ induces destruction of $\beta$-cells and the insulin production is almost

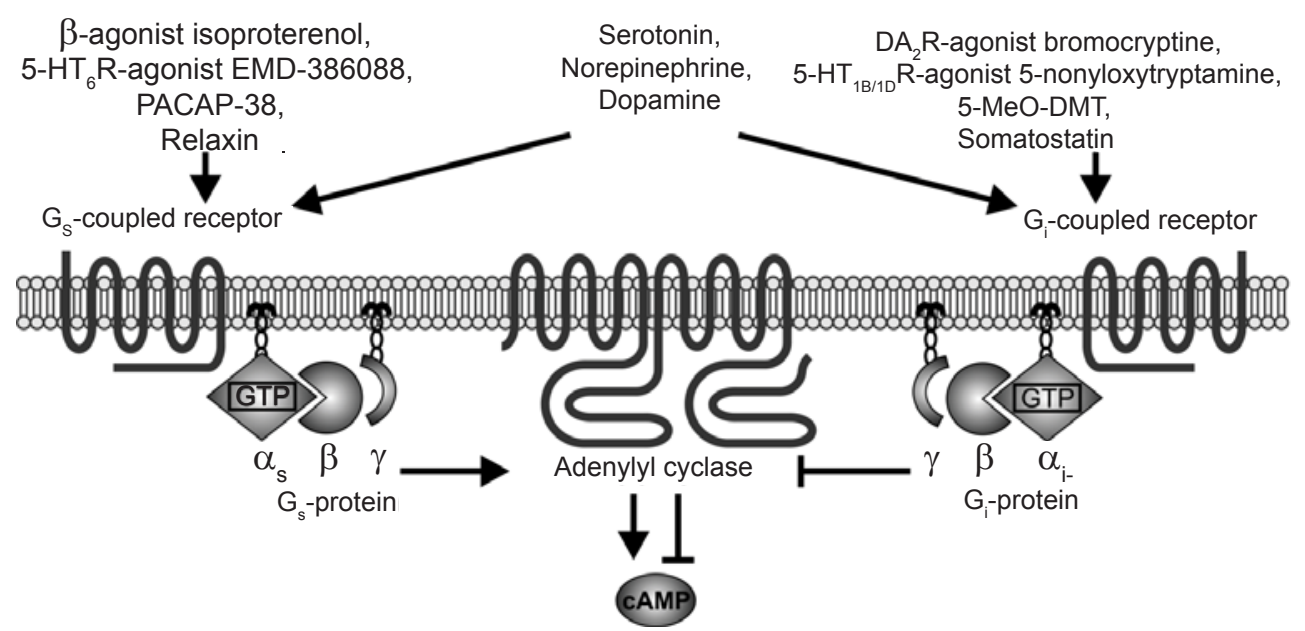

Figure 1: Transduction of hormonal signals generated by biogenic amines, polypeptide hormones and their synthetic analogues via AC signaling system Isoproterenol, EMD-386088, PACAP-38 and relaxin interact with Gs protein-coupled receptors, stimulate AC activity, increase the intracellular level of second messenger CAMP and trigger CAMP-dependent signaling cascades involved in the regulation of growth, differentiation and metabolism of the neuronal and glial cells. Bromocryptine, 5-nonyloxytryptamine, 5-MeO-DMT and somatostatin interact with Gi protein-coupled receptors, inhibit AC activity and block cAMP-dependent pathways. Serotonin, norepinephrine and dopamine are capable of interacting with both Gs protein- and Gi protein-coupled receptors. 
Citation: Shpakov AO, Derkach KV, Chistyakova OV, Sukhov IB, Shipilov VN, et al. (2012) The Brain Adenylyl Cyclase Signaling System and Cognitive Functions in Rats with Neonatal Diabetes under the Influence of Intranasal Serotonin. J Metabolic Synd 1:104. doi:10.4172/21670943.1000104

Page 3 of 9

completely blocked. However, at the early stages of development of rats (the first week after birth), a partial restoration of insulin-producing function of $\beta$-cells can occur due to their regeneration [21,22]. As a rule, $50-70 \%$ of STZ treatment infant rats show signs of T2DM on reaching the age of $2.5-3$ months [23]. In our experiments $70 \%$ of 3 month-old STZ-treated rats had glucose tolerance, as was assessed in the glucose tolerance test (GTT), and these animals were used for experiments (Groups D and D-S). Alongside, we observed moderate hyperglycemia (the fasting glucose concentration was no higher than $7 \mathrm{mM}$ ), moderate hypoinsulinemia and the increased plasma levels of triglycerides and HDL-cholesterol. This is in good agreement with the corresponding parameters of the rats with neonatal model of T2DM obtained by the other authors $[19,20,23]$. In our case impaired glucose tolerance can be associated with moderate hypoinsulinemia, which was due to damage of $\beta$-cells in the neonatal period of development and with insulin resistance, which was due to decrease of insulin signaling in the tissues of rats with STZ-induced neonatal DM [14,24]. Earlier, we showed that the insulin binding capacity of insulin receptors in the liver membranes of rats with neonatal model of T2DM was lower compared with healthy animals due to a smaller number of insulin receptors with high and low affinity [14].

\section{Plasma glucose, insulin, triglycerides and HDL-cholesterol measurements}

The glucose in the whole blood from the tail vein was measured using test strips One Touch Ultra (USA) and a glucometer (Life Scan Johnson \& Johnson, Denmark). The insulin concentration in rat serum was determined using Rat Insulin ELISA (Mercodia AB, Sweden). Triglycerides was determined by Trinder-based GPO-PAP colorimetric end-point method and high density lipoproteins(HDL)-cholesterol by direct clearance method using kits of Randox Laboratories Ltd. (UK) and Sapphire 400 automated clinical chemistry analyzer (Niigata Mechatronics Co., Ltd., Japan). The whole blood was obtained from the tail vein under local (sc) anesthesia with $2 \%$ Lidocaine per $2-4 \mathrm{mg} / \mathrm{kg}$ of body weight.

\section{Intranasal delivery of serotonin}

Intranasal delivery of serotonin to 6-months old healthy rats (Group C-S) and to diabetic rats of the same age with 3-months neonatal DM (Group D-S) was carried out according to Thorne and coworkers [25]. Serotonin at final concentration of $1 \mathrm{mg} / \mathrm{ml}$ was dissolved in saline, $\mathrm{pH}$ 4.5. Each rat was placed in a supine position and then an average of $20 \mu \mathrm{l}$ of serotonin solution containing $20 \mu \mathrm{g}$ of hormone was administrated by Eppendorf pipette as $5 \mu \mathrm{l}$ drops in each nostril, in turn, every 1-2 min. Control animals were given the equal volume of saline, $\mathrm{pH}$ 4.5. All in all, the IS treatment covered 8 weeks (one week prior to physiological experiments and 7 weeks in the course of experiments).

\section{Chemicals and radiochemicals}

The chemicals used in the study were purchased from SigmaAldrich (St. Louis, MO, USA) and Calbiochem (San Diego, CA, USA). STZ, GppNHp, somatostatin-14, PACAP-38, serotonin, norepinephrine, dopamine, isoproterenol, bromocryptine, and 5-MeO-DMT were purchased from Sigma-Aldrich (St. Louis, MO, USA). 5-Nonyloxytryptamine and EMD-386088 were purchased from Tocris Cookson Ltd. (United Kingdom). Human relaxin-2 was kindly provided by Prof. J. Wade (Howard Florey Institute, University of Melbourne, Australia). [ $\alpha-32 \mathrm{P}]-\mathrm{ATP}(4 \mathrm{Ci} / \mathrm{mmol})$ was purchased from Isotope Company (St. Petersburg, Russia), $\beta, \gamma$-imido $\left[8-{ }^{3} \mathrm{H}\right]$-guanosine5 '-triphosphate $\left(\left[8-{ }^{3} \mathrm{H}\right]-\mathrm{GppNHp}\right)(5 \mathrm{Ci} / \mathrm{mmol})$ was from Amersham
(UK); the type HA $0.45 \mu \mathrm{m}$ nitrocellulose filters were from SigmaAldrich Chemie GmbH (Germany).

\section{Synaptosomal membrane preparation}

The 8-months old diabetic and non-diabetic animals were decapitated under anesthetics (a mixture of Ketamine and Xylazine at the doses of 90 and $10 \mathrm{mg} / \mathrm{kg}$ of body weight, respectively) 24 hours after the last intranasal administration of serotonin or saline, and the brain was rapidly removed and frozen to prepare synaptosomal membrane fractions. The preparation of the rat brain membranes was obtained as described earlier [26]. The brain tissues were dissected on ice and homogenized with a Polytron in 30 volumes of ice-cold $50 \mathrm{mM}$ Tris- $\mathrm{HCl}$ buffer ( $\mathrm{pH} 7.4$ ) containing $10 \mathrm{mM} \mathrm{MgCl}, 2 \mathrm{mM}$ EGTA, $10 \%(\mathrm{w} / \mathrm{v})$ sucrose and a cocktail of protease inhibitors (Buffer A). The obtained material underwent centrifugation at $4^{\circ} \mathrm{C}$. The crude homogenate was centrifuged at $1000 \times \mathrm{g}$ for $10 \mathrm{~min}$; the resulting pellet was discarded and the supernatant was centrifuged at $9000 \times \mathrm{g}$ for 20 min. The pellet was resuspended in Buffer A (without sucrose) and centrifuged at $35000 \times \mathrm{g}$ for $10 \mathrm{~min}$. The final pellet was resuspended in $50 \mathrm{mM}$ Tris- $\mathrm{HCl}$ buffer $(\mathrm{pH}$ 7.4) to produce the membrane fraction with a protein concentration range $1-3 \mathrm{mg} / \mathrm{ml}$ and stored at $-70^{\circ} \mathrm{C}$. The protein concentration of each membrane preparation in all experiments was measured by the method of Lowry and colleagues, using BSA as a standard.

\section{Adenylyl cyclase assay}

The AC (EC 4.6.1.1) activity was measured as described earlier [26]. The reaction mixture (final volume $50 \mu \mathrm{l}$ ) contained $50 \mathrm{mM}$ Tris- $\mathrm{HCl}$ (pH 7.5), $5 \mathrm{mM} \mathrm{MgCl}, 1 \mathrm{mM}$ ATP, $1 \mu \mathrm{Ci}\left[\alpha^{-32} \mathrm{P}\right]$-ATP, $0.1 \mathrm{mM}$ cAMP, $20 \mathrm{mM}$ creatine phosphate, $0.2 \mathrm{mg} / \mathrm{ml}$ creatine phosphokinase, and $15-45 \mu \mathrm{g}$ of the membrane protein. Incubation was carried out at $37^{\circ} \mathrm{C}$ for $10 \mathrm{~min}$. The reaction was initiated by the addition of membrane protein and terminated by the addition of $100 \mu \mathrm{l}$ of $0.5 \mathrm{M} \mathrm{HCl}$, followed by immersing the tubes with mixture in a boiling water bath for $6 \mathrm{~min}$. $100 \mu \mathrm{l}$ of $1.5 \mathrm{M}$ imidazole was added to each tube. In these conditions the $\mathrm{AC}$ activity was linear. $\left[{ }^{32} \mathrm{P}\right]$-cAMP formed as a result of the enzyme reaction was separated using column chromatography. The samples were placed on neutral alumina columns and cAMP was eluted with $8 \mathrm{ml}$ of $10 \mathrm{mM}$ imidazole- $\mathrm{HCl}$ buffer ( $\mathrm{pH}$ 7.4). The eluates were collected in scintillation vials and counted using a LS 6500 scintillation counter (Beckman Instruments Inc., USA). Each assay was carried out in triplicate at least three times, and the results were expressed as $\mathrm{pmol} \mathrm{cAMP} / \mathrm{min}$ per $\mathrm{mg}$ of membrane protein. The basal activity was measured in the absence of hormones, GppNHp and forskolin. To measure the AC inhibitory effect of hormone, the enzyme was preactivated by diterpene forskolin $\left(10^{-5} \mathrm{M}\right)$.

\section{GppNHp binding assay}

$\left[8-{ }^{3} \mathrm{H}\right]-\mathrm{GppNHp}$ binding to heterotrimeric $\mathrm{G}$ proteins was determined as described earlier [27]. The reaction mixture (final volume $50 \mu \mathrm{l}$ ) contained $25 \mathrm{mM}$ HEPES-Na buffer ( $\mathrm{pH}$ 7.4), $1 \mathrm{mM}$ EDTA, $5 \mathrm{mM} \mathrm{MgCl}, 100 \mathrm{mM} \mathrm{NaCl}, 1 \mathrm{mM}$ dithiothreitol, $1 \mu \mathrm{M}$ GppNHp, $0.1 \% \mathrm{BSA}, 0.5-1 \mu \mathrm{Ci}\left[8-{ }^{3} \mathrm{H}\right]-\mathrm{GppNHp}$. The reaction was started by the addition of $50-100 \mu \mathrm{g}$ of membrane protein and carried out at $30^{\circ} \mathrm{C}$ for $45 \mathrm{~min}$. The reaction mixture was incubated and rapidly diluted with $100 \mu \mathrm{l}$ of the washing buffer $\left(20 \mathrm{mM} \mathrm{K}-\mathrm{Na}^{+}\right.$phosphate buffer, $\left.\mathrm{pH} 8.0\right)$ containing $0.1 \%$ Lubrol-PX and the samples were filtered under vacuum through $0.45 \mu \mathrm{m}$ nitrocellulose filters (type HA). In each case the filter was washed three times with $2 \mathrm{ml}$ of washing buffer and dried. The filter-bound radioactivity was estimated in a toluene scintillator using a LKB 1209/1215 RackBeta scintillation counter. Unlabeled $10 \mathrm{mM}$ 
Citation: Shpakov AO, Derkach KV, Chistyakova OV, Sukhov IB, Shipilov VN, et al. (2012) The Brain Adenylyl Cyclase Signaling System and Cognitive Functions in Rats with Neonatal Diabetes under the Influence of Intranasal Serotonin. J Metabolic Synd 1:104. doi:10.4172/21670943.1000104

Page 4 of 9

GppNHp was added to the reaction mixture to estimate non-specific binding. The specific GppNHp binding was assessed as the difference between a total and non-specific binding. Each assay was carried out in triplicate at least three times and the results were expressed as pmol $\left[8-{ }^{3} \mathrm{H}\right]-\mathrm{GppNHp}$ per mg of membrane protein.

\section{Morris water-maze test}

Throughout the behavioral experiments the groups of 6-8 months old diabetic and non-diabetic rats, IS-treated and untreated, were investigated. Prior to the experiments the animals were acclimated to handling over a week. A spatial training of rats was performed in MWM test [28]. The test efficiency was estimated by how long it took the animals swimming in a circular pool $(120 \mathrm{~cm}$ in diameter and 30 $\mathrm{cm}$ in height filled with turbid water with chalk at $24 \pm 1^{\circ} \mathrm{C}$ ) to find a $13 \mathrm{~cm}$ diameter hidden platform located $2 \mathrm{~cm}$ below the water level.

In the first series of experiments the animals swam daily for five days. Each rat had four attempts of 120 seconds for search of the hidden platform from four starting points. The animals were allowed to swim until either they located the platform, climbing upon it, or when 120 seconds elapsed. If the rats did not find the platform, they were compulsorily placed on it. Between the attempts the animals remained on the platform for 30 seconds rest. Post-testing, rats were placed under a heating lamp to get warm. The escape latency, the length of search path, and search speed during each trial were taken as indicators of successful formation and consolidation of spatial memory and learning.

A month later the testing was repeated (the second series) and the rats were given the trials similar to those of the first series. In addition, on the fifth day of the first and second series 40 minutes after the basic testing the rats were placed for 60 seconds in the pool where the hidden platform was removed and the number of annulus crossings over the previous platform location was recorded. This parameter provides replicates of the experiment for estimation of the strength and accuracy of the memory of the previous platform location. The swimming path and the escape latency were recorded by video camera for each rat during the trial. The obtained data were processed using Real Timer software 1.2 (Open Science Ltd., Russia) and Smart Junior (Panlab, S.L.U., Harvard Apparatus, USA).

\section{Statistical analysis}

The data was presented as the mean \pm SD. Testing the assumption of normality was performed by using Shapiro-Wilk test. The results of the test confirmed that the obtained data is a sample from a normal distribution at $\alpha=0.05$. The difference in the basal activity of AC or the basal level of GppNHp binding in the tissue membrane fractions of control and diabetic animals as well as the difference in the AC activity or GppNHp binding in the membrane fractions treated by hormones and non-hormonal AC regulators in each case was statistically assessed using one-way analysis of variance (ANOVA) and considered significant at $P<0.05$. The analysis of the data obtained in MWM test was carried out using one-way analysis of variance (ANOVA) followed by Student's Newman-Keuls post hoc test or unpaired t-test as required, and the difference was considered significant at $P<0.05$.

\section{Results}

\section{Neonatal model of T2DM and IS treatment}

In our biochemical and physiological experiments were used 6-8-months old diabetic rats with neonatal DM duration of 3-5 months. Prior to IS treatment the body weight of 6-months old diabetic rats was higher as compared with control animals of the same age and following 8-weeks treatment with IS the difference in the body weight between IS-treated diabetic (D-S) and healthy (C-S) animals decreased (Table 1). In diabetic rats the level of fasting blood glucose was no higher than $7 \mathrm{mM}$ (moderate hyperglycemia) and the level of plasma insulin was slightly decreased (moderate hypoinsulinemia). The level of triglycerides in the blood of the diabetic rats was significantly increased compared with control animals ( $1.50 \pm 0.19$ vs. $0.88 \pm 0.12$ $\mathrm{nM}, P<0.001)$, while the increase of the level of HDL-cholesterol in $\mathrm{DM}$ was not significant $(0.55 \pm 0.08$ vs. $0.46 \pm 0.07 \mathrm{mM})$. These data is in good agreement with characteristics of the rat neonatal DM obtained by the other authors $[19,23]$. In our case, the IS treatment had a weak influence on glucose, insulin, triglycerides and HDL-cholesterol concentrations both in diabetic and control rats. In glucose tolerance test 2 hours after glucose load the concentration of plasma glucose in control rats reached normal level, while in diabetic rats remained much higher compared with control ( $13.5 \pm 2.6$ vs. $5.3 \pm 1.0 \mathrm{mM}$ ) (Figure 2). In the IS-treated diabetic rats the concentration of glucose in glucose tolerance test also did not decrease to normal level and was higher than in Group C-S $(11.1 \pm 2.0$ vs. $5.7 \pm 1.5 \mathrm{mM})$. At the same time,

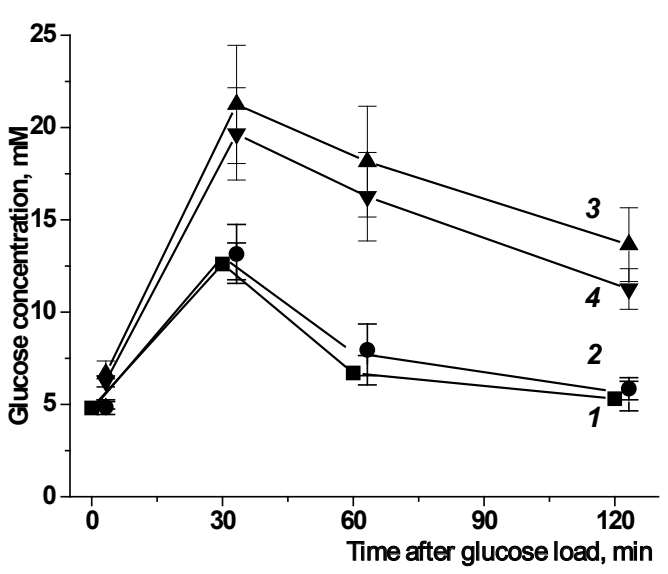

Figure 2; The concentration of plasma glucose in glucose tolerance test. 1 - Group C; 2 - Group C-S; 3 - Group D; 4 - Group D-S. The data is presented as the mean \pm SEM of three individual experiments.

\begin{tabular}{|c|c|c|c|c|c|c|}
\hline & \multicolumn{2}{|c|}{ Body weight, g } & \multicolumn{2}{|c|}{ Plasma glucose, mM } & \multicolumn{2}{|c|}{ Plasma insulin, ng/mL } \\
\hline & 6 months & 8 months & 6 months & 8 months & 6 months & 8 months \\
\hline$C(n=9)$ & $226 \pm 19$ & $259 \pm 1^{8 \&}$ & $5.0 \pm 0.7$ & $4.7 \pm 0.9^{8}$ & $2.4 \pm 0.3$ & $2.3 \pm 0.3^{\&}$ \\
\hline C-S $(n=8)$ & $219 \pm 17$ & $256 \pm 15^{88}$ & $5.1 \pm 0.6$ & $4.5 \pm 0.5^{8 \&}$ & $2.4 \pm 0.4$ & $2.1 \pm 0.2^{8 \&}$ \\
\hline$D(n=7)$ & $261 \pm 22$ & $296 \pm 26^{\&}$ & $6.9 \pm 1.1^{*}$ & $6.5 \pm 1.2^{* \star \&}$ & $1.4 \pm 0.3^{*}$ & $1.6 \pm 0.4^{\&}$ \\
\hline $\mathrm{D}-\mathrm{S}(\mathrm{n}=7)$ & $268 \pm 12^{++}$ & $278 \pm 16^{8 \&}$ & $6.9 \pm 1.4^{+}$ & $6.0 \pm 1.2+8 \&$ & $1.5 \pm 0.4^{+}$ & $1.8 \pm 0.3^{8 \&}$ \\
\hline
\end{tabular}

C - control animals, C-S - IS-treated healthy animals, D - diabetic animals; D-S - IS-treated diabetic animals. \& - control and diabetic rats after 8-weeks intranasal administration of saline instead of serotonin; $8 \&$ - healthy and diabetic rats after 8-weeks IS treatment $(20 \mu \mathrm{g} /$ rat every day). Values are the mean \pm SD of three individual experiments. *, ${ }^{* *}$ - the statistically significant difference between Groups D and $\mathrm{C}$ at $P<0.05$ and $P<0.01$; +, ++ - the statistically significant difference between Groups D-S and C-S at $P<0.05$ and $P<0.01$, respectively.

Table 1: The body weight, fasting glucose and insulin levels in 6- and 8-months healthy and diabetic rats. 
Citation: Shpakov AO, Derkach KV, Chistyakova OV, Sukhov IB, Shipilov VN, et al. (2012) The Brain Adenylyl Cyclase Signaling System and Cognitive Functions in Rats with Neonatal Diabetes under the Influence of Intranasal Serotonin. J Metabolic Synd 1:104. doi:10.4172/21670943.1000104

Page 5 of 9

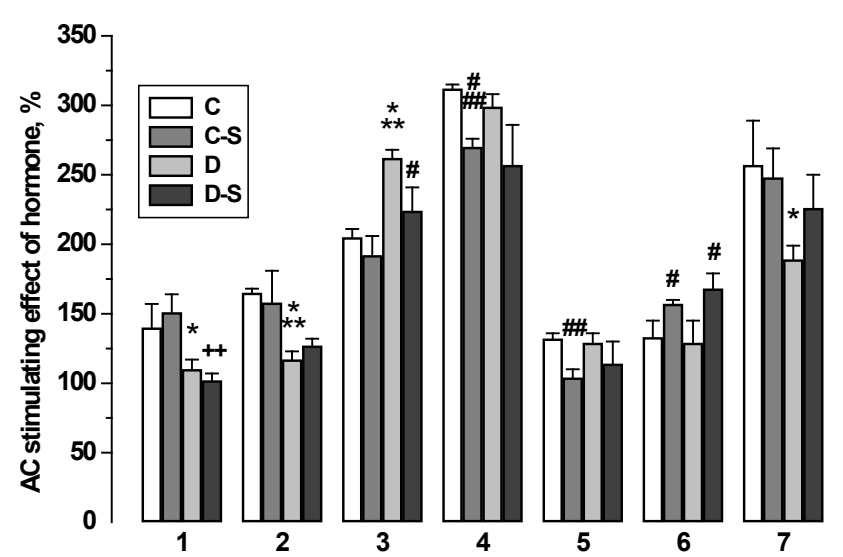

Figure 3: The stimulating effects of hormones on AC activity in the brain of untreated and IS-treated diabetic and control rats.

1 - norepinephrine; 2 - isoproterenol; 3 - dopamine; 4 - serotonin; 5 - EMD386088 ( $10^{-5} \mathrm{M}$ each); 6 - PACAP-38, $10^{-7} \mathrm{M} ; 7$ - relaxin, $10^{-8} \mathrm{M}$.

C - control animals, C-S - IS-treated healthy animals, D - diabetic animals; D-S - IS-treated diabetic animals. Values are the mean \pm SD of three individual experiments, each performed in triplicate.

$*{ }^{* * *}$ - the statistically significant difference between Groups $D$ and $C$ at $P<$ 0.05 and $P<0.001$; \#, \#\#, \#\# - the statistically significant difference between Groups D-S and D or Groups C-S and C at $P<0.05, P<0.01$ and $P<0.001$, respectively; ${ }^{++}$- the statistically significant difference between Groups D-S and C-S at $P<0.01$.

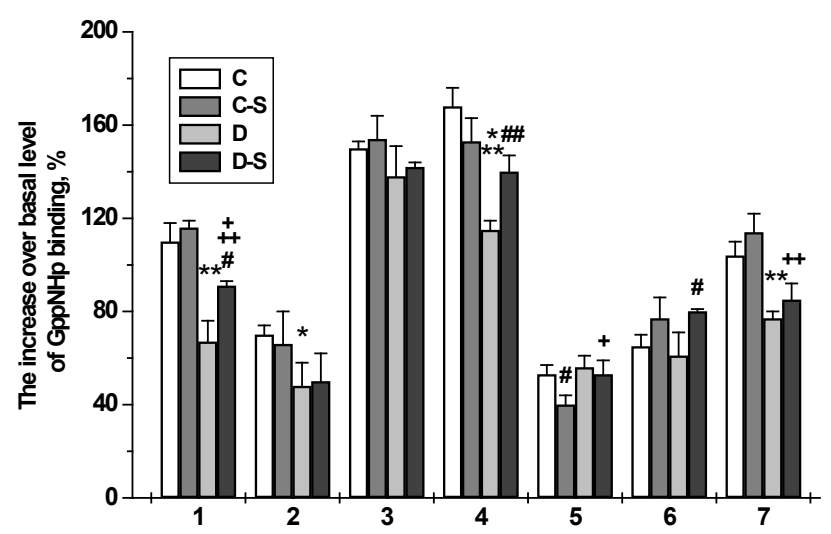

Figure 4: The hormone-induced increase of GppNHp binding in the brain of untreated and IS-treated diabetic and control rats.

1 - norepinephrine; 2 - isoproterenol; 3 - dopamine; 4 - serotonin; 5 - EMD386088 ( $10^{-5} \mathrm{M}$ each); 6 - PACAP-38, $10^{-7} \mathrm{M} ; 7$ - relaxin, $10^{-8} \mathrm{M}$

The basal level of GppNHp binding is taken as $100 \%$. Values are the mean \pm SD of three individual experiments, each performed in triplicate.

${ }^{*}{ }^{* *},{ }^{* * *}$ - the statistically significant difference between Groups $\mathrm{D}$ and $\mathrm{C}$ at $P$ $<0.05, P<0.01$ and $P<0.001$; \#, \#\# - the statistically significant difference between Groups D-S and D or Groups C-S and C at $P<0.05$ and $P<0.01$; $^{+,++}$ ${ }^{+++}$- the statistically significant difference between Groups D-S and C-S at $P<$ $0.05, P<0.01$ and $P<0.001$, respectively.

in Group D-S the plasma glucose level was $18 \%$ lower compared with Group D, which indicates a rather moderate IS-induced improvement in sensitivity of the peripheral tissues to insulin.

The influence of IS on the basal and GppNHp- and forskolinstimulated adenylyl cyclase activities and on GppNHp binding in the brain of diabetic and control rats

The basal AC activity in the brain of diabetic rats did not differ significantly from control ( $23.0 \pm 1.7 \mathrm{vs.} 24.4 \pm 1.5 \mathrm{pmol} \mathrm{cAMP} / \mathrm{min}$ per $\mathrm{mg}$ of membrane protein). Non-hydrolysable analog of GTP, GppNHp $\left(10^{-5} \mathrm{M}\right)$, activator of $\mathrm{G}_{\mathrm{s}}$ proteins, stimulated $\mathrm{AC}$ activity in control and diabetic rats by 188 and $197 \%$, and forskolin $\left(10^{-5} \mathrm{M}\right)$ acting directly on the catalytic site of the enzyme stimulated AC activity by 281 and 273 $\%$, respectively. The basal AC activity in the brain of IS-treated diabetic and control rats was $21.3 \pm 2.0$ and $20.9 \pm 1.3 \mathrm{pmol} \mathrm{cAMP} / \mathrm{min}$ per $\mathrm{mg}$ of membrane protein, which did not differ significantly from the basal activity of the enzyme in the untreated animals. The IS treatment did not influence the stimulating effects of GppNHp and forskolin on AC activity.

The basal level of GppNHp binding in the brain of diabetic animals did not differ significantly from control ( $4.25 \pm 0.28 \mathrm{vs.} 4.51 \pm 0.26 \mathrm{pmol}$ $\left[8-{ }^{3} \mathrm{H}\right]-\mathrm{GppNHp} / \mathrm{mg}$ of membrane protein), and 8-weeks IS treatment increased, but not significantly, it in Groups D-S and C-S, which was now $4.55 \pm 0.19$ and $4.73 \pm 0.22 \mathrm{pmol}\left[8-{ }^{3} \mathrm{H}\right]-\mathrm{GppNHp} / \mathrm{mg}$ of membrane protein, respectively. This prompts a suggestion that in the brain of rats with neonatal model of T2DM the functional activity of AC system in the basal state and/or under stimulation by non-hormonal agents does not undergo significant alterations, and IS did not significantly affect $\mathrm{AC}$ and $\mathrm{G}_{\mathrm{s}}$ protein, the catalytic and the transducing components of this system.

The regulation of $\mathrm{AC}$ system by hormones acting via $\mathrm{G}_{\mathrm{s}}$ coupled receptors in DM under the influence of IS

In our experiments the biogenic amines and their analogues, such as norepinephrine, $\beta$-AR-agonist isoproterenol, dopamine, serotonin and 5- $\mathrm{HT}_{6} \mathrm{R}$-agonist EMD-386088, as well as the polypeptide hormones PACAP-38 and relaxin stimulated AC activity and GppNHp binding in the brain of both diabetic and control animals (Figures 3,4). In the diabetic brain AC stimulating effects of relaxin and AR-agonists isoproterenol and norepinephrine were decreased, the corresponding effect of dopamine was on the contrary increased, and AC effects of 5-HTR-agonists and PACAP-38 remained unchanged. The stimulating effects of relaxin, AR-agonists and serotonin on GppNHp binding were decreased in the diabetic brain, and the corresponding effects of the other hormones were close to control.

The IS treatment of control and diabetic rats led to a decrease of AC stimulating effects of serotonin and EMD-386088 and to an increase of the corresponding effect of PACAP-38. In the diabetic brain the stimulating effects of serotonin and PACAP-38 on GppNHp binding were increased, whereas the corresponding effect induced by EMD-386088 did not change significantly. IS led to partial restoration of both AC effect of relaxin decreased in the diabetic brain and the corresponding effect of dopamine increased in DM. IS did not significantly affect AC stimulating effects of AR ligands that in DM are decreased, but increased norepinephrine-induced stimulation of GppNHp binding (Figures 3,4). Thus, in the brain of rats with neonatal T2DM the functional activity of some signaling pathways mediating AC stimulation by hormones of different nature is changed. The changes we identified were hormone-specific, being as a rule associated with pathways regulated by AR ligands and relaxin. IS restored the transduction of AC stimulating signals in the diabetic brain and also affected AC stimulating effects of 5-HTR agonists and PACAP-38 in the healthy rats treated by IS.

The regulation of $A C$ system by hormones acting via $G_{i}$ coupled receptors in DM under the influence of IS

The hormonal regulators acting via $\mathrm{G}_{\mathrm{i}}$-coupled receptors - the biogenic amines and their synthetic analogues, such as norepinephrine, dopamine, serotonin, selective $5-\mathrm{HT}_{1 \mathrm{~B} / \mathrm{D}} \mathrm{R}$ agonist 5-nonyloxytryptamine, $\quad 5-\mathrm{HT}_{1 / 2} \mathrm{R}$ agonist 5-methoxy- 
Citation: Shpakov AO, Derkach KV, Chistyakova OV, Sukhov IB, Shipilov VN, et al. (2012) The Brain Adenylyl Cyclase Signaling System and Cognitive Functions in Rats with Neonatal Diabetes under the Influence of Intranasal Serotonin. J Metabolic Synd 1:104. doi:10.4172/21670943.1000104

Page 6 of

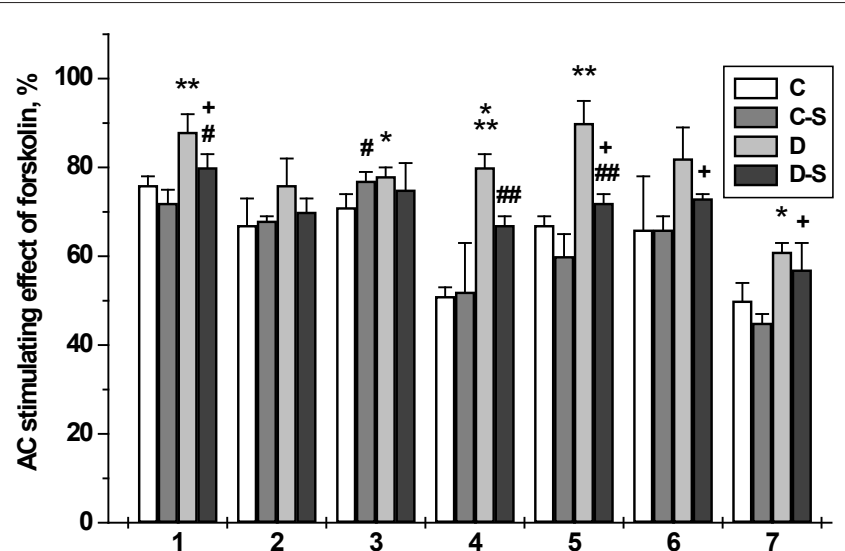

Figure 5: The inhibitory effects of hormones on forskolin-stimulated AC activity in the brain of untreated and IS-treated diabetic and control rats.

1 - norepinephrine; 2 -dopamine; 3 - bromocriptine; 4 - serotonin; 5 - 5-nonyloxytryptamine; 6 - 5-MeO-DMT (10-5 M each); 7 - somatostatin, $10^{-6} \mathrm{M}$. The stimulating effect of forskolin $\left(10^{-5} \mathrm{M}\right)$ on the basal $A C$ activity is taken as $100 \%$. Values are the mean \pm SD of three individual experiments, each performed in triplicate.

${ }^{*},{ }^{* *},{ }^{* *}$ - the statistically significant difference between Groups $\mathrm{D}$ and $\mathrm{C}$ at $P$ $<0.05, P<0.01$ and $P<0.001$; \#, \#\# - the statistically significant difference between Groups D-S and D or Groups C-S and C at $P<0.05$ and $P<0.01$, respectively; ${ }^{+}$- the statistically significant difference between Groups D-S and C-S at $P<0.05$

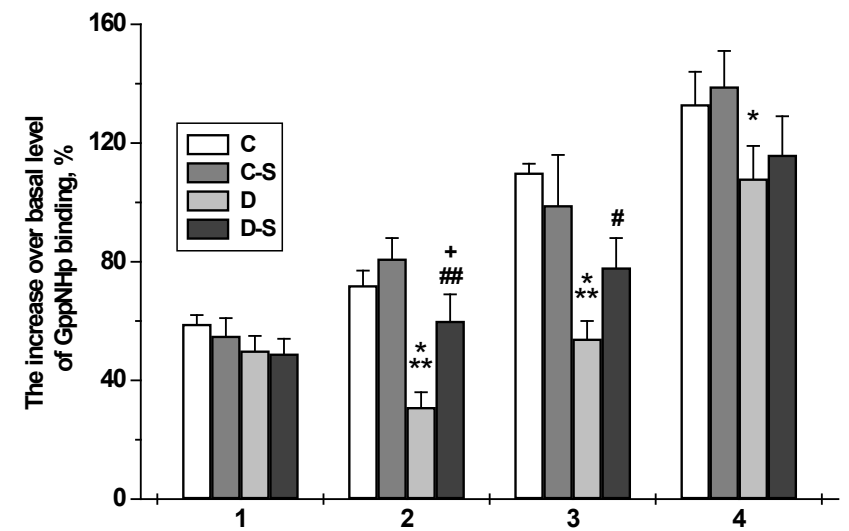

Figure 6: The increase of basal GppNHp binding by hormones activating preferably $G_{i}$ proteins

1 - bromocriptine; 2 - 5-nonyloxytryptamine; 3 - 5-MeO-DMT (10-5 M each); 4 - somatostatin, $10^{-6} \mathrm{M}$

The basal level of GppNHp binding is taken as $100 \%$. Values are the mean \pm $\mathrm{SD}$ of three individual experiments, each performed in triplicate.

${ }^{*},{ }^{* * *}$ - the statistically significant difference between Groups $\mathrm{D}$ and $\mathrm{C}$ at $P<$ 0.05 and $P<0.001$, respectively; \#, \#\# - the statistically significant difference between Groups D-S and D or Groups C-S and C at $P<0.05$ and $P<0.01$, respectively; + - the statistically significant difference between Groups D-S and C-S at $P<0.05$

$\mathrm{N}, \mathrm{N}$-dimethyltryptamine, $\mathrm{DA}_{2} \mathrm{R}$ agonist bromocriptine, and the neuropeptide somatostatin - all decreased forskolin-stimulated AC activity in the synaptosomal membranes in control rats (Figure 5). Besides, these hormones increased basal GppNHp binding (Figures 4,6). In Group D the inhibiting effects of hormones on AC activity and their stimulating effects on GppNHp binding were markedly decreased, especially in the case of serotonin and 5-HT R agonists. In the diabetic brain the stimulating effects of norepinephrine, serotonin, 5-nonyloxytryptamine, 5-methoxy-N,N-dimethyltryptamine and somatostatin on GppNHp binding reached $61,68,43,49$ and $81 \%$ of those in Group C. The corresponding effects of dopamine and $\mathrm{DA}_{2} \mathrm{R}-$ agonist bromocriptine changed a little.

IS weakly influenced the regulatory effects of hormones inhibiting AC via Gi proteins in the brain of animals in Group C-S. In Group D-S the IS treatment led to a significant restoration of both AC inhibitory effects of hormones and their stimulation of GTP-binding (Figures 4,5,6). The stimulating effects of norepinephrine, serotonin, 5-nonyloxytryptamine, 5-MeO-DMT and somatostatin on GppNHp binding in Group D-S covered 78, 92, 74, 79 and $83 \%$ of those in Group C-S. These values are higher compared with those of untreated diabetic animals, especialy in the case of 5-HTR agonists. According to the obtained data, IS gives a significant impact to the stimulation of GppNHp binding of $G_{i}$ proteins by hormones inhibiting AC activity in the diabetic brain, and this effect is most pronounced in serotoninregulated $\mathrm{G}_{i}$-coupled AC pathway.

\section{The spatial memory and learning of diabetic and control rats} under the influence of IS

The learning process was estimated according to the duration and dynamics of the latent period for finding the hidden platform. The latent period in Group D in the first series was 3.5 times and in the second series 4-4.5 times longer compared with Group $\mathrm{C}$ and the dynamics of time reduction in locating the platform was less pronounced (Figure 7). IS did not change the duration and dynamics of the latent period in control animals, but significantly improved the learning process in diabetic rats. On the $4^{\text {th }}$ day of the first series the escape latency reached the plateau and the information about the location of platform was maintained throughout the experiment. In Group D-S the latent period in both series was lower compared with Group D and the difference was significant $(P<0.05)$. The maximal effect of IS was 4 times, at most, the reduction of the latent period on the first day of the second series ( $35^{\text {th }}$ day of MWM experiment). In both series there was a significant difference in the trajectories of swimming to the remote platform in Groups D and C, especially in the beginning of the second series (Figure 8). IS did not influence the swimming tracking in Group C-S,

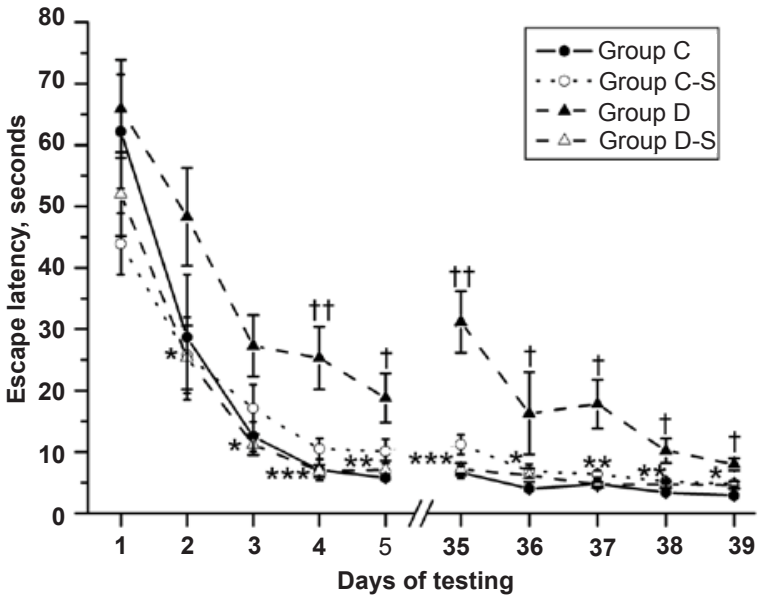

Figure 7: The duration and dynamics of latent period to find the platform by untreated and IS-treated diabetic and control rats in MWM test.

1 - Group C; 2 - Group C-S; 3 - Group D; 4 - Group D-S. Abscissa - the days of testing; ordinate - the escape latency, seconds. The first series covers days $1-5$; the second days 35-39.

The data is presented as the mean \pm SEM. $\dagger$, $† \dagger-$ denotes the statistically significant difference between Groups $D$ and $C$ at $P<0.05$ and $P<0.01$; * **, *** - denotes the statistically significant difference between Groups D-S and D at $\mathrm{P}<0.05, P<0.01$ and $P<0.001$, respectively. 
Citation: Shpakov AO, Derkach KV, Chistyakova OV, Sukhov IB, Shipilov VN, et al. (2012) The Brain Adenylyl Cyclase Signaling System and Cognitive Functions in Rats with Neonatal Diabetes under the Influence of Intranasal Serotonin. J Metabolic Synd 1:104. doi:10.4172/21670943.1000104

Page 7 of 9

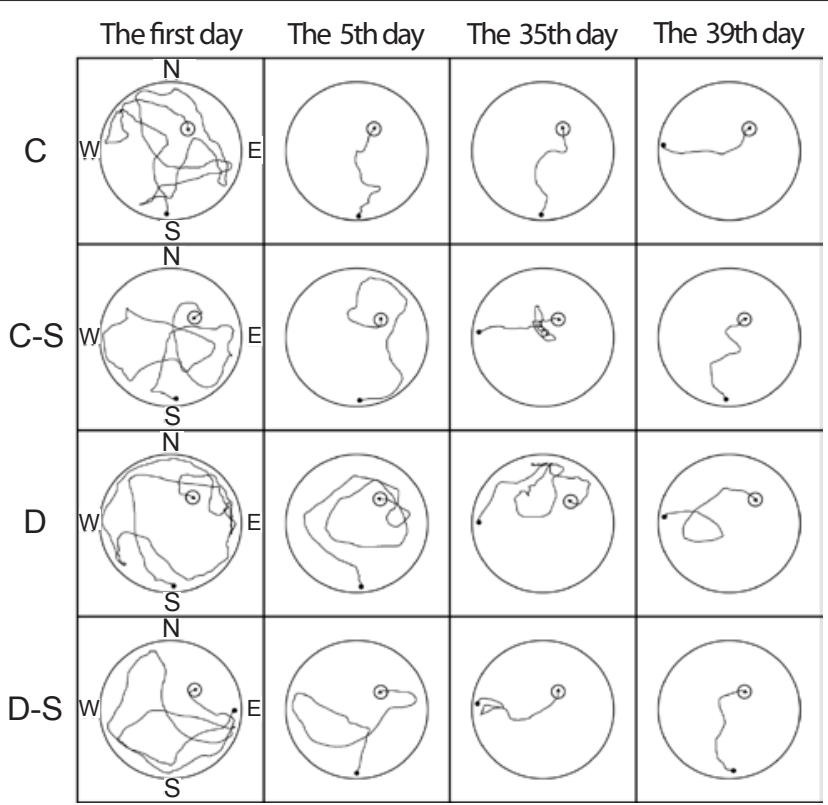

Figure 8: Typical swimming trajectories of untreated and IS-treated healthy and diabetic rats in MWM test.

N - "North", S - "South", W - "West", E - "East".

\begin{tabular}{|l|l|l|}
\hline Rats & The first series, 5th day & The second series, 39th day \\
\hline Group C $(n=9)$ & $5.8 \pm 2.0$ & $7.0 \pm 1.0$ \\
\hline Group C-S $(n=8)$ & $6.8 \pm 1.5$ & $6.6 \pm 2.8$ \\
\hline Group D $(n=7)$ & $3.1 \pm 2.5$ & $4.6 \pm 1.8^{* *}$ \\
\hline Group D-S $(n=7)$ & $5.4 \pm 1.6^{\#+}$ & $7.9 \pm 2.3^{\#}$ \\
\hline
\end{tabular}

The number of annulus crossings over the platform location was recorded on the fifth day of the first and second series when 40 minutes after the basic testing the animals were placed for 60 seconds in the pool where the hidden platform was removed.

C - control animals, C-S - IS-treated healthy animals, D - diabetic animals; $\mathrm{D}-\mathrm{S}-$ IS-treated diabetic animals. Values are the mean $\pm S D$ of three individual experiments. ** - the statistically significant difference between Groups D and C at $\mathrm{P}<0.01$; \#, \# - the statistically significant difference between Groups D-S and $D$ at $P<0.05$ and $P<0.01$, respectively; + - the statistically significant difference between Groups D-S and C-S at $\mathrm{P}<0.05$

Table 2: The number of annulus crossings in the experiments with IS-treated and untreated control and diabetic rats in Morris water-maze test.

but in Group D-S the trajectories were much shorter compared with Group D and similar to those of control rats.

On the last day of testing in the first and the second series there was no difference in the number of annulus crossings between Groups $\mathrm{C}$ and C-S (Table 2). However, in diabetic rats there was a $45 \%$ decrease in the first series and a $40 \%$ decrease in the second, compared with Group $\mathrm{C}$ and the treatment with IS significantly increased these parameters in both series. In the first and the second series the number of annulus crossings in Group D-S, on average, exceeded 1.7 times that of Group D. Paradoxically, in the second series the number of annulus crossings in Group D-S was larger than in Groups C and C-S (Table 2). This furnishes grounds for us to say that IS improves the long-term spatial memory in rats with neonatal model of T2DM, making it similar to healthy animals. A decrease of time to search the platform and an increase of the number of annulus crossings in Group D-S shows the serotonin-induced improvement of cognitive functions in diabetic rats.

\section{Discussion}

Cognitive deficit with impaired abstract reasoning and complex psychomotor functioning are likely to occur on the late stages of T2DM due to the triggering of neurodegenerative processes in the brain of diabetic patients [29]. However, the molecular mechanisms responsible for these processes in the diabetic brain are poorly understood, which hampers the development of effective approaches for the management and prevention of DM-induced CNS complications. Currently, it is commonly accepted that in DM especially disturbed is the signaling network regulated by insulin, insulin-like growth factor-1 and leptin, the principal hormones to be affected in diabetes; this leads to the disturbances of the growth, differentiation, metabolic and apoptotic processes in neuronal and glial cells. However, in addition to these hormones, there are a large number of other hormones and growth factors, as well as the signaling cascades regulated by them which are also involved in the etiology and pathogenesis of DM and its complications [5].

In this work we showed that in the brain of female rats with neonatal T2DM the brain signaling cascades regulated by biogenic amines and polypeptide hormones do indeed undergo a significant change and the most pronounced alterations are manifested in $G$ protein-coupled cascades. The changes were found to occur in the AC system sensitive to AR agonists, serotonin, dopamine, and polypeptide hormones, which agrees very well with the data on the alterations and abnormalities in the adrenergic, serotonergic, dopaminergic and peptidergic neurotransmitter systems in the diabetic brain and on their role in the development of neurodegeneration [5].

We showed that in the diabetic brain the stimulating effects of norepinephrine and isoproterenol on AC activity and GppNHp binding mediated via $\mathrm{G}_{\mathrm{s}}$-coupled $\beta$-AR are reduced, so is the AC inhibitory effect of norepinephrine mediated via $G_{i}$-coupled $\alpha_{2}$-AR. The abnormalities in adrenergic signaling in DM are likely, on the one hand, to have a negative influence on the synaptic transmission provoked by impairment of the mechanism involving increase of intracellular CAMP concentration and protein synthesis de novo, which leads to memory impairment and cognitive deficit [30], and on the other, to be responsible for DM-associated disturbances in the cerebral microvessels whose functions are controlled via different signaling systems, the adrenergic in particular [31]. It was shown earlier that in the hypothalamus of 4-16-weeks old $d b / d b$ mice the number of $\beta$-ARs was reduced, which demonstrates a marked modification of the adrenergic signaling [32]. In the brainstem of rats with STZ-induced T1DM the affinity of $\alpha_{2}$-ARs to agonists was significantly reduced and restored by insulin treatment [33]. The number of $\beta$-ARs in cerebral microvessels of fatty $(f a / f a)$ and STZ rats is markedly decreased, and isoproterenol-stimulated AC activity in the microvessels of diabetic rats is much lower than that in control, giving evidence for the weakening of $\beta$-AR-mediated regulation of cAMP-dependent signaling [31].

In our study pronounced alterations of $\mathrm{G}_{\text {- }}$-coupled serotonin signaling in the brain of diabetic rats are likely to be one of the direct causes of DM-induced behavioral abnormalities, so much so as the brain serotonergic system regulates many physiological functions, and the changes in serotonergic transmission in the diabetic brain provoke disturbances of neuronal processing and the altered plasticity of neurotransmission. We showed that the regulatory effects of $5-\mathrm{HT}_{1 \mathrm{~B} / 1 \mathrm{D}} \mathrm{R}-$ agonist 5-nonyloxytryptamine and 5- $\mathrm{HT}_{1 / 2} \mathrm{R}$-agonist 5-MeO-DMT were markedly reduced, which indicates a weakening of serotonin signaling mediated via $5-\mathrm{HT}_{1} \mathrm{R}$ in the brain of rats with neonatal T2DM. The data is available that the flat body posture of STZ diabetic and non-diabetic rats induced by $5-\mathrm{HT}_{1 \mathrm{~A}} \mathrm{R}$ agonist 8 -hydroxy-2-(dipropylamino)tetralin hydrobromide (8-OH-DPAT) changed, but not alike, which means that STZ-induced T1DM profoundly affects the sensitivity to drugs acting 
Citation: Shpakov AO, Derkach KV, Chistyakova OV, Sukhov IB, Shipilov VN, et al. (2012) The Brain Adenylyl Cyclase Signaling System and Cognitive Functions in Rats with Neonatal Diabetes under the Influence of Intranasal Serotonin. J Metabolic Synd 1:104. doi:10.4172/21670943.1000104

Page 8 of 9

via $5-\mathrm{HT}_{1 \mathrm{~A}} \mathrm{R}$ [34]. One-week insulin treatment restored 8-OH-DPATinduced behavioral effects. We showed earlier that the sensitivity of $\mathrm{G}_{\mathrm{i}}$ coupled AC system to agonists of 5- $\mathrm{HT}_{1} \mathrm{R}$ was significantly decreased in the brain of STZ rats with T1DM [35], but there was no alteration of AC sensitivity to agonists of $\mathrm{G}_{\mathrm{s}}$ protein-coupled 5-HTR. This is consistent with the data obtained in the present study, i.e. that the efficiency of transduction of AC stimulating serotonin signal in the brain of rats with neonatal T2DM is not altered as compared with control. It seems quite possible that the decrease of efficiency of $\mathrm{G}_{\mathrm{i}}$-coupled serotonin signaling pathways may well be associated with reduced expression and with decreased functional activity of $G_{i}$ proteins, which might indeed be the case as in the brain of rats with neonatal DM was also detected a decrease of activity of the $\mathrm{G}_{\mathrm{i}}$-coupled cascades which undergo regulation by norepinephrine and somatostatin.

However, studying dopamine signaling in the diabetic brain, we showed that regulatory effects of dopamine and $\mathrm{DA}_{2} \mathrm{R}$-agonist bromocriptine on $A C$ system mediated via $G_{i}$-coupled $D_{2} R$ did not change significantly, while stimulating effects of dopamine on this system mediated via $G_{s}$-coupled $D_{1} R$ increased. In our view, here a decreased expression of $G_{i}$ proteins was fully compensated by an increased expression of $\mathrm{DA}_{2} \mathrm{R}$ or by the changes of their binding characteristics. This suggestion finds confirmation in the recent investigations showing that $\mathrm{B}_{\max }$ of a total DAR binding and the expression of $\mathrm{DA}_{2} \mathrm{R}$ in the cerebral cortex of STZ rats with T1DM are increased significantly [36]. In the diabetic brain of T1DM rats the expression of $\mathrm{DA}_{1} \mathrm{R}$ was also increased, which explains the increase of stimulating influence of dopamine on $\mathrm{AC}$, as in the case of rats with neonatal DM in our investigation.

As far as the role of polypeptide hormones somatostatin, PACAP-38 and relaxin in the functioning of CNS is concerned, they are shown to be involved in the regulation of neuronal differentiation, synaptic plasticity, cognitive functions [37-39]. However, the data on functional activity of the brain signaling systems regulated by these hormones in $\mathrm{DM}$ are scarce. The information is available now that the intracerebral level of somatostatin and the expression of some types of brain somatostatin receptors are reduced in animal models of T1DM [40]. We showed that in the brain of rats with neonatal T2DM the regulatory action of somatostatin and relaxin on AC activity is decreased. This allowed a suggestion that somatostatin- and relaxin-sensitive AC system is involved in pathogenesis of T2DM and is a candidate to serve as a marker of this disease. At the same time, we found no significant changes in the response of AC in the diabetic brain to PACAP-38. It seems likely that the maintenance of AC stimulating effect of PACAP-38 is due to its important role in the protection of the brain from damage and neurodegenerative changes induced by DM [41].

The well-coordinated regulation of AC system in the normal brain is disrupted in T2DM, and the synergistic effect of alterations in this system leads to neurodegenerative changes in different brain areas. This is confirmed by our data on the impairment of the cognitive functions in rats with neonatal T2DM in MWM test. The diabetic rats demonstrated the problems in intellectual development and learning. The deterioration of the time allocated to search the platform and the increase of swimming trajectory in the second series indicates the impairment of spatial memory in neonatal T2DM. A number of reports are available describing a cognitive deficit associated with abnormalities in the hippocampus activity in obese rats [42]. Female KKAy mice with hyperinsulinemia and impaired glucose tolerance showed a significant impairment of cognitive functions evaluated by the shuttle avoidance and MWM tests [43]. The rats with T2DM induced by high fat diet and low-dose STZ treatment had deterioration of stroke-induced brain damage and cognitive deficit, as was illustrated by the impairment of the performance of rats in the MWM test [44].

One of the usual approaches used to restore the neuronal network in T2DM is the treatment of diabetic patients with glucose-lowering drugs and, at the late stages of disease, with insulin. Another approach is to treat patients with neurohormones and drugs controlling their synthesis, secretion and uptake, these substances can be used alone or in combination with insulin therapy. The best studied among them are the selective 5-HT reuptake inhibitors having antidepressant activity and $\mathrm{DA}_{2} \mathrm{R}$ agonist bromocriptine widely used in the treatment of hyperprolactinemia, galactorrhoea and Parkinson disease [16,17]. The 5-HT reuptake inhibitors contribute to lowering the level of hyperglycemia, improve metabolic control through their positive effect on weight loss, thereby improving insulin resistance, and restore cognitive functions impaired in DM. The treatment of 60 patients with depression associated with T1DM and T2DM by fluoxetine, selective 5-HT reuptake inhibitor, reduced depressive symptoms and increased the sensitivity of the brain and the peripheral tissues to insulin [16] Consequently, the approach leading to an increase of the brain 5-HT level is a successful strategy to treat DM [17]. Proceeding from this data, we applied IS for restoration of activity of the brain AC system and improvement of cognitive deficit of rats with neonatal T2DM. The intranasal route of serotonin administration has been chosen so that the hormone could be delivered to the brain areas, the targets of this action, more effectively. This method is successfully used to treat migraine by $5-\mathrm{HT}_{1 \mathrm{~B} / \mathrm{D}} \mathrm{R}$-agonist sumatriptan and its analogues [45]. In the diabetic brain IS restores hormonal sensitivity of AC system, and its positive effect was observed in the case of hormones, especially of serotonin and 5 - $\mathrm{HT}_{1} \mathrm{R}$ agonists, acting via $\mathrm{G}_{\mathrm{i}}$ proteins. A considerable restoration of 5-HT R-mediated signaling in the brain of IS-treated diabetic rats should be ascribed to an increase of the activity of serotonin-sensitive $\mathrm{AC}$ system as a result of normalization of the expression of components of this system, and to an increase of the efficiency of interaction between serotonin-regulated and the other signaling systems due to restoration of integrative signaling network in the neuronal and the glial cells impaired in DM. The restoration of the brain AC signaling regulated by neurotransmitters and polypeptide neurohormones leads to the improvement of cognitive functions. The evidence for this is considerable improvement of spatial memory and learning in IS-treated diabetic rats in MWM test. The cognitive functions we evaluated in this test did not differ from those of healthy rats treated as well as untreated with IS.

Summing up, in the brain of diabetic rats with neonatal T2DM the functional activity of hormone-sensitive AC signaling system is subject to changes, the most significant alterations being observed in $\mathrm{G}_{\text {- }}$-coupled cascades that mediate the inhibition of AC activity. These alterations were associated with cognitive deficit and manifested as impaired learning and spatial memory. The intranasal delivery of serotonin improves both the brain AC system and cognitive functions of diabetic rats, which opens up a new avenue to correct and prevent the alterations and disturbances in the brain signaling and to improve cognitive functions in T2DM.

\section{Acknowledgment}

This work was supported by Grant No. 09-04-00746 from the Russian Foundation of Basic Research and Program "Fundamental Sciences - Medicine" (2009-2011). The authors are grateful to Inga Menina for linguistic assistance.

\section{References}

1. Stiles MC, Seaquist ER (2010) Cerebral structural and functional changes in type 1 diabetes. Minerva Med 101: 105-114.

2. Biessels G, Smale S, Duis S, Kamal A, Gispen W (2001) The effect of Y-linolenic 
Citation: Shpakov AO, Derkach KV, Chistyakova OV, Sukhov IB, Shipilov VN, et al. (2012) The Brain Adenylyl Cyclase Signaling System and Cognitive Functions in Rats with Neonatal Diabetes under the Influence of Intranasal Serotonin. J Metabolic Synd 1:104. doi:10.4172/ 2167-0943.1000104

Page 9 of 9

acid- $\alpha$-lipoic acid on functional deficits in the peripheral and central nervous system of streptozotocin-diabetic rats. J Neurol Sci 182: 99-106

3. Scheen AJ (2010) Central nervous system: a conductor orchestrating metabolic regulations harmed by both hyperglycaemia and hypoglycaemia. Diabetes Metab 36: S31-S38.

4. Muniyappa R, Montagnani M, Koh KK, Quon MJ (2007) Cardiovascular actions of insulin. Endocr Rev 28: 463-491.

5. Shpakov A, Chistyakova O, Derkach K, Bondareva V (2011) Hormonal signaling systems of the brain in diabetes mellitus: Neurodegenerative Diseases. (R.C. Chang, ed.), Intech Open Access Publisher, Rijeka, Croatia. 349-386.

6. Palmer TM, Taberner PV, Houslay MD (1992) Alterations in G-protein expression, $\mathrm{Gi}$ function and stimulatory receptor-mediated regulation of adipocyte adenylyl cyclase in a model of insulin-resistant diabetes with obesity. Cell Signal 4: 365-377.

7. Hashim S, Li Y, Nagakura A, Takeo S, Anand-Srivastava MB (2004) Modulation of G-protein expression and adenylyl cyclase signaling by high glucose in vascular smooth muscle. Cardiovasc Res 63: 709-718.

8. Shpakov AO, Kuznetsova LA, Plesneva SA, Bondareva VM, Guryanov IA et al. (2006) Decrease in functional activity of G-proteins hormone-sensitive adenylate cyclase signaling system, during experimental type II diabetes mellitus. Bull Exp Biol Med 142: 685-689.

9. Shpakov A, Kuznetsova L, Plesneva S, Kolychev A, Bondareva V, et al. (2006) Functional defects in adenylyl cyclase signaling mechanisms of insulin and relaxin action in skeletal muscles of rat with streptozotocin type 1 diabetes. Cent Eur J Biol 1: 530-544.

10. Shpakov AO, Kuznetsova LA, Plesneva SA, Pertseva MN (2007) The disturbance of the transduction of adenylyl cyclase inhibiting hormonal signal in myocardium and brain of rats with experimental type II diabetes. Tsitologiia 49: $442-450$

11. Shpakov AO, Chistyakova OV, Derkach KV, Moiseyuk IV, Bondareva VM (2012) Intranasal insulin affects adenylyl cyclase system in rat tissues in neonatal diabetes. Central Eur J Biol 7: 33-47.

12. Ovalle $F(2010)$ Clinical approach to the patient with diabetes mellitus and very high insulin requirements. Diabetes Res Clin Pract 90: 231-242.

13. Henkin RI (2010) Intranasal insulin: from nose to brain. Nutrition 26: 624-633.

14. Chistyakova OV, Bondareva VM, Shipilov VN, Sukhov IB, Shpakov AO (2011) Intranasal administration of the insulin eliminates long-term memory deficits in rats with neonatal diabetes mellitus. Dokl Biochem Biophys 440: 216-218.

15. Kerr J, Timpe E, Petkewicz K (2010) Bromocriptine mesylate for glycemic management in type 2 diabetes mellitus. Ann Pharmacother 44: 1777-1785.

16. Lustman P, Freedland K, Griffith L, Clouse R (2000) Fluoxetine for depression in diabetes: a randomized double-blind placebo-controlled trial. Diabetes Care 23: 618-623.

17. Zhou L, Sutton GM, Rochford JJ, Semple RK, Lam DD, et al. (2007) Serotonin $2 \mathrm{C}$ receptor agonists improve type 2 diabetes via melanocortin-4 receptor signaling pathways. Cell Metab 6: 398-405.

18. Guidelines for the treatment of animals in behavior research and teaching (2006) Animal Behaviour. 71: 245-253.

19. Hemmings S, Spafford D (2000) Neonatal STZ model of type II diabetes mellitus in the Fischer 344 rat: characteristics and assessment of the status of the hepatic adrenergic receptors. Int J Biochem Cell Biol 32: 905-919.

20. Sharma AK, Srinivasan BP (2009) Triple verses glimepiride plus metformin therapy on cardiovascular risk biomarkers and diabetic cardiomyopathy in insulin resistance type 2 diabetes mellitus rats. Eur J Pharm Sci 38: 433-444.

21. Thyssen S, Arany E, Hill DJ (2006) Ontogeny of regeneration of beta-cells in the neonatal rat after treatment with streptozotocin. Endocrinology 147: 23462356.

22. Nicholson JM, Arany EJ, Hill DJ (2010) Changes in islet microvasculature following streptozotocin-induced beta-cell loss and subsequent replacement in the neonatal rat. Exp Biol Med (Maywood) 235: 189-198.

23. Blondel O, Bailbé D, Portha B (1989) Relation of insulin deficiency to impaired insulin action in NIDDM adult rats given streptozocin as neonates. Diabetes 38: $610-617$

24. Suryanarayana P, Patil MA, Reddy GB (2011) Insulin resistance mediated biochemical alterations in eye lens of neonatal streptozotocin-induced diabetic rat. Indian J Exp Biol 49: 749-755.
25. Thorne RG, Pronk GJ, Padmanabhan V, Frey WH (2004) Delivery of insulin-like growth factor-I to the rat brain and spinal cord along olfactory and trigeminal pathways following intranasal administration. Neuroscience 127: 481-496.

26. Shpakov A, Shpakova E, Tarasenko I, Derkach K, Vlasov G (2010) The peptides mimicking the third intracellular loop of 5-hydroxytryptamine receptors of the types $1 \mathrm{~B}$ and 6 selectively activate $\mathrm{G}$ proteins and receptor-specifically inhibit serotonin signaling via the adenylyl cyclase system. Int J Pept Res Ther 16: 95-105.

27. Shpakov A, Shpakova E, Tarasenko I, Derkach K, Chistyakova O, et al. (2011) The influence of peptides corresponding to the third intracellular loop of luteinizing hormone receptor on basal and hormone-stimulated activity of the adenylyl cyclase signaling system. Global J Biochem 2: 59-73.

28. Van Dam D, Lenders G, De Deyn PP (2006) Effect of Morris water maze diameter on visual-spatial learning in different mouse strains. Neurobiol Learn Mem 85: 164-172.

29. Biessels GJ, Deary IJ, Ryan CM (2008) Cognition and diabetes: a lifespan perspective. Lancet Neurol 7: 184-190.

30. Tully K, Bolshakov VY (2010) Emotional enhancement of memory: how norepinephrine enables synaptic plasticity. Mol Brain 3: 15.

31. Mooradian AD, Scarpace PJ (1992) Beta-adrenergic receptor activity of cerebral microvessels in experimental diabetes mellitus. Brain Res 583: 155160.

32. Garris DR (1990) Age- and diabetes-associated alterations in regional brain norepinephrine concentrations and adrenergic receptor populations in C57BL/ KsJ mice. Brain Res Dev Brain Res 51: 161-166.

33. Padayatti PS, Paulose CS (1999) $\alpha_{2}$-Adrenergic and high affinity serotonergic receptor changes in the brain stem of streptozotocin-induced diabetic rats. Life Sci 65: 403-414.

34. Li JX, France CP (2008) Food restriction and streptozotocin treatment decrease 5-HT1A and 5-HT2A receptor-mediated behavioral effects in rats. Behav Pharmacol 19: 292-297.

35. Shpakov AO, Kuznetsova LA, Plesneva SA, Guryanov IA, Vlasov GP, et al. (2007) Identification of disturbances in hormone-sensitive adenylyl cyclase system in the tissues of rats with types 1 and 2 diabetes using functional probes and synthetic peptides. Tekhnologii zhivykh system 4: 96-108.

36. Robinson R, Krishnakumar A, Paulose CS (2009) Enhanced dopamine D1 and D2 receptor gene expression in the hippocampus of hypoglycaemic and diabetic rats. Cell Mol Neurobiol 29: 365-372.

37. Epelbaum J, Guillou J, Gastambide F, Hoyer D, Duron E, et al. (2009) Somatostatin, Alzheimer's disease and cognition: an old story coming of age? Prog Neurobiol 89: 153-161.

38. McGowan BM, Minnion JS, Murphy KG, White NE, Roy D, et al. (2010) Central and peripheral administration of human relaxin-2 to adult male rats inhibits food intake. Diabetes Obes Metab 12: 1090-1096.

39. Moody TW, Ito T, Osefo N, Jensen RT (2011) VIP and PACAP: recent insights into their functions/roles in physiology and disease from molecular and genetic studies. Curr Opin Endocrinol Diabetes Obes 18: 61-67.

40. Bruno JF, Xu Y, Song J, Berelowitz M (1994) Pituitary and hypothalamic somatostatin receptor subtype messenger ribonucleic acid expression in the food-deprived and diabetic rat. Endocrinology 135: 1787-1792.

41. Reglodi D, Kiss P, Lubics A, Tamas A (2011) Review on the protective effects of PACAP in models of neurodegenerative diseases in vitro and in vivo. Curr Pharm Des 17: 962-972.

42. Greenwood CE, Winocur G (2005) High-fat diets, insulin resistance and declining cognitive function. Neurobiol Aging 26: 42-45.

43. Sakata A, Mogi M, Iwanami J, Tsukuda K, Min LJ, et al. (2010) Female exhibited severe cognitive impairment in type 2 diabetes mellitus mice. Life Sci 86: 638645.

44. Zhang T, Pan BS, Zhao B, Zhang LM, Huang YL, et al. (2009) Exacerbation of poststroke dementia by type 2 diabetes is associated with synergistic increases of beta-secretase activation and beta-amyloid generation in rat brains. Neuroscience 161: 1045-1056.

45. Cittadini E, May A, Straube A, Evers S, Bussone G, et al. (2006) Effectiveness of intranasal zolmitriptan in acute cluster headache: a randomized, placebocontrolled, double-blind crossover study. Arch Neurol 63: 1537-1542. 